Article

\title{
The Concept, Technical System and Heat Transfer Analysis on Phase-Change Heat Storage Backfill for Exploitation of Geothermal Energy
}

\author{
Xiaoyan Zhang ${ }^{1, *}$, Muyan Xu ${ }^{1}$, Li Liu $^{1}$, Lang Liu ${ }^{1,2, *}$, Mei Wang ${ }^{1}{ }^{\circledR}$, Haiwei Ji ${ }^{1}$ \\ and KI-IL Song ${ }^{3}(\mathbb{D}$ \\ 1 College of Energy, Xi'an University of Science and Technology, Xi'an 710054, China; \\ 18203057015@stu.xust.edu.cn (M.X.); 17203057007@stu.xust.edu.cn (L.L.); wangmei029@xust.edu.cn (M.W.); \\ jihaiwei@xust.edu.cn (H.J.) \\ 2 Key Laboratory of Western Mines and Hazards Prevention, Ministry of Education, Xi'an 710054, China \\ 3 Department of Civil Engineering, Inha University, Incheon 402-751, Korea; ksong@inha.ac.kr \\ * Correspondence: zhangxy0629@xust.edu.cn (X.Z.); liulang@xust.edu.cn (L.L.)
}

Received: 23 July 2020; Accepted: 9 September 2020; Published: 11 September 2020

\begin{abstract}
In view of high ground stress, high geothermal temperature, and thermal hazard during deep mineral resource exploitation, the concept of phase-change heat storage backfill was put forward in this study. Further, the corresponding technical system was constructed and the main content involved in technical system, which is the optimized proportion of the backfill slurry added with phase-change materials (PCMs), was examined. Moreover, we elaborated upon the collaborative optimization of a backfill body's mechanical and thermal properties and the mutual cooperation on backfill mining, geothermal energy exploitation, and simultaneous stope cooling. The heat transfer behavior of a backfill body plays a key role in technology system. We numerically simulated the heat transfer among a backfill body, surrounding rock, and airflow in the heat storage process, as well as the heat transfer between backfill body and cold fluid during the heat release process. The temperature distribution of a backfill body at different heat storage/heat release times-i.e., the temperature distribution and its evolution - with heat transfer were revealed and analyzed. This study can provide theoretical guidance for a phase-change heat storage backfill, as it has an important significance for the collaborative exploitation of mineral resources and geothermal energy.
\end{abstract}

Keywords: phase-change; heat storage/heat release; backfill body; collaborative exploitation; stope cooling

\section{Introduction}

The exploitation and utilization of deep mineral resources has become an inevitable trend with the gradual reduction and exhaustion of shallow mineral resources. The exploitation and utilization of deep mineral resources is also in line with the strategic requirements of "deep space, deep sea, deep blue, and deep land" put forward in "The National Medium-and Long-Term Program for Science and Technology Development (2006-2020)". The mining technology of deep mineral resources is an important field of "deep land" exploration and it is the high-end development of modern mining technology. Deep mining is in the special environment of "three high", which is high ground stress, high geothermal temperature, and high mine depth. Thus, it is bound to bring many scientific and technological problems to the mining of deep mineral resources and also seriously affect the safety, efficiency, and cost of mine production, even related to the feasibility of resource exploitation $[1,2]$.

Backfill mining technology is an effective way to solve the problem of high ground stress, control the ground subsidence, and improve the mining rate of resources when mining deep mineral 
resources. Moreover, it does not cause serious damage to the ecological environment. With the rapid development of the mining industry, the situation of mineral resources is becoming more and more complex, and the geographical location and environmental conditions are also different for different mines. Therefore, it is necessary not only to select the corresponding backfill mining technology according to the specific mining conditions, but also to reasonably select the backfill materials in combination with the actual situation, so as to ensure its quality and performance can meet the mining operation need. The innovation and development of backfill materials explores a new way for resource reuse of solid wastes in mines, such as tailings, fly ash, and waste rocks. Under the premise of controlling ground subsidence, the solid waste of mines should be selected as backfill materials so backfill mining is also an effective means to make solid wastes harmless and reusable, and realize "green mining" in mines [3,4].

For deep mining, the ground temperature rises and heat releases to the stope from surrounding rocks; this is the main source of thermal hazard in the mine. In addition, other heat sources, such as air compression and mechanical equipment, lead to an increase of stope temperature. The deeper the mining depth, the higher the temperature of surrounding rock, and the more serious the thermal hazard. In many countries, thermal hazard in mines appears one after another [5-8]. In South Africa, gold mines are about $2800 \mathrm{~m}$ deep and the temperature of rock reaches $75^{\circ} \mathrm{C}$, whereas the Mponeng gold mine is about $4100 \mathrm{~m}$ deep and the temperature of rock reaches $66^{\circ} \mathrm{C}$. In Japan, the Chang-pan coal mines rock temperature reaches $42-48^{\circ} \mathrm{C}$ and the water temperature reaches $72{ }^{\circ} \mathrm{C}$. In the Feng-yu lead-zinc mine in Hokkaido, the temperature of rock reaches $69-130^{\circ} \mathrm{C}$. The average geothermal temperature per kilometer is $30-40{ }^{\circ} \mathrm{C}$ in Russia, with individual areas reaching $52^{\circ} \mathrm{C}$. In India, where gold mine are about $3000 \mathrm{~m}$ deep, the geothermal temperature reaches $70^{\circ} \mathrm{C}$. In China, some mines are one $\mathrm{km}$ deep, the rock temperature has exceeded $50{ }^{\circ} \mathrm{C}$. In addition, many countries (e.g., Zambia, Mexico, Nicaragua, Poland, Germany) have thermal hazards in mines. However, the high geothermal temperature, which leads to the occurrence of thermal hazard, provides a good condition for geothermal energy exploitation and geothermal energ, as a clean and renewable energy, which belongs to the category of mining [9-11]. For mineral resources and geothermal energy to coexist in the deep layer, it is necessary to build respective mining systems. Based on this common characteristics, if geothermal energy can be simultaneously exploited with the help of the deep mineral resource systems and the collaborative exploitation of geothermal energy with mineral resources can be realized, then many advantages will be had [12].

* It is unnecessary for drilling engineering to occur on the earth's surface, as it can save the cost of geothermal energy exploitation.

* Deep space has a considerable scale. High temperature rocks provide a continuous heat source for geothermal energy exploitation.

* Deep mining has complete elevation and transportation, as well as complete electric power, water supply, and drainage system, which provides pipeline layout safeguard and power supply for geothermal energy exploitation.

* After mining is completed, the abandoned mine can be used as a geothermal energy plant.

By focusing on the collaborative exploitation of deep mineral resources and geothermal energy, the concept of phase-change heat storage backfill was put forward. The corresponding technical system was constructed and several parts involved in the technical system were analyzed. Aiming at the key of the technical system (I.E., the heat storage/heat release process of the backfill body), the heat transfer model of the phase-change backfill body was established and the temperature distribution and its evolution in the backfill body was numerically simulated and analyzed during the heat storage process/heat release. This study can provide the theoretical framework for phase-change heat storage backfill technology and technical guidance for the collaborative exploitation of deep mineral resources and geothermal energy. 


\section{The Concept of Phase-Change Heat Storage Backfill}

\subsection{The Control of Thermal Hazard Development from Single Treatment to Combined with Geothermal Energy Exploitation}

With the continuous extension of mineral resource exploitation into the deep layer, thermal hazards have become a major problem that restricts mining safety $[5,13]$. For thermal hazards, the control methods have gradually developed from initial ventilation, heat source control, personal protection, and other non-mechanical refrigeration to mechanical refrigeration technology, which can produce cold air, cold water, and cold ice to cooling the airflow in stope $[5,14]$. However, the mechanical refrigeration leads to an increase in mining cost and has high power consumption [15,16]. For the exploitation of mineral resources in the deep layer, the geothermal heat deteriorates working conditions and is a main thermal hazard heat source [14]. However, due to the problems of environmental pollution and energy shortage caused by excessive fossil fuel exploitation and consumption, geothermal energy has attracted attention as a clean and renewable green energy source $[17,18]$. The exploitation and utilization of geothermal energy can weaken the main thermal hazard heat source in deep mines, make passive prevention and control of thermal hazard gradually develop towards proactive geothermal energy exploitation combined with mine cooling, and provide a feasible technical way to prevent and control thermal hazards in deep mines.

\subsection{The Extension and Integration from Deep Mineral Mining to Deep Geothermal Energy Exploitation}

High geothermal temperature, high ground stress, rock physical property deterioration, mine lifting, and other problems in deep mines increases the cost of mines. However, the geothermal energy stored in the deep layer is a clean and renewable energy. Moreover, the reserve is very abundant, the advantage of environmental protection is obvious, the application field is wide, and it is a reliable, stable, and impervious to climatic conditions during exploitation and utilization $[10,19,20]$. The exploitation of geothermal energy requires a heat transfer fluid (cold fluid) to bring thermal energy to the ground. Therefore, it is necessary to drill well, reinforce well, and complete well when extracting thermal energy from the subsurface target layer. The depth of drilling well for extracting geothermal energy generally is between $1000 \mathrm{~m}$ and $3000 \mathrm{~m}$. Most, however, are around $2000 \mathrm{~m}$ and a few are more than $3000 \mathrm{~m}$. At present, the cost of drilling and completing well nearly accounts for the half of the total cost in geothermal energy exploitation [21]. With the development of exploitation technology, drilling well can extend to the deeper layer, which increases the cost. If the exploitation of geothermal energy can be combined with mineral resources in the deep layer, underground tunnels, complete elevation, transportation, power, water supply, and drainage systems can provide good conditions for piping layout, power supply, and the cycle of the heat transfer fluid in geothermal energy exploitation. In such a scenario, the cost of geothermal energy exploitation is be greatly reduced [22-24].

\subsection{The Connotation of Phase-Change Heat Storage Backfill}

Backfill mining technology has a long history in domestic and foreign metal mines, with the development of backfill mining theory and increasing requirements of deep mining. Backfill mining technology has developed from simple accumulative backfill (e.g., dry back-filling of waste rock, water-sand backfill) to structural backfill (e.g., cemented paste backfill), and then gradually transitioned to functional backfill [12]. So-called functional backfill means that the backfill body is formed by the solidification of backfill slurry and should not only have the basic function of realizing ground stress management and preventing ground subsidence, but also have some special function beyond transition, thus realizing the organic unification of each function. Based on the combination of controlling thermal hazards, exploiting geothermal energy, and extending from deep mineral mining to deep geothermal energy exploitation, that latent heat storage with phase-change materials is a promising technique to handle the intermittent issue of renewable energy [25-28]. This paper puts forth the concept of 
phase-change heat storage backfill (Figure 1). When backfill mining is conducted, a certain dosage of PCM (phase-change materials) is added into backfill slurry under the condition of satisfying the requirements of mechanical properties for backfill mining. The backfill body is formed via solidified backfill slurry with good thermal properties. Geothermal energy can be exploited by heat storage and release from the backfill body during heat storage. The backfill body absorbs heat from surrounding rocks and stope airflow, reducing heat from surrounding rock to airflow, so it is realized of simultaneous stope cooling.

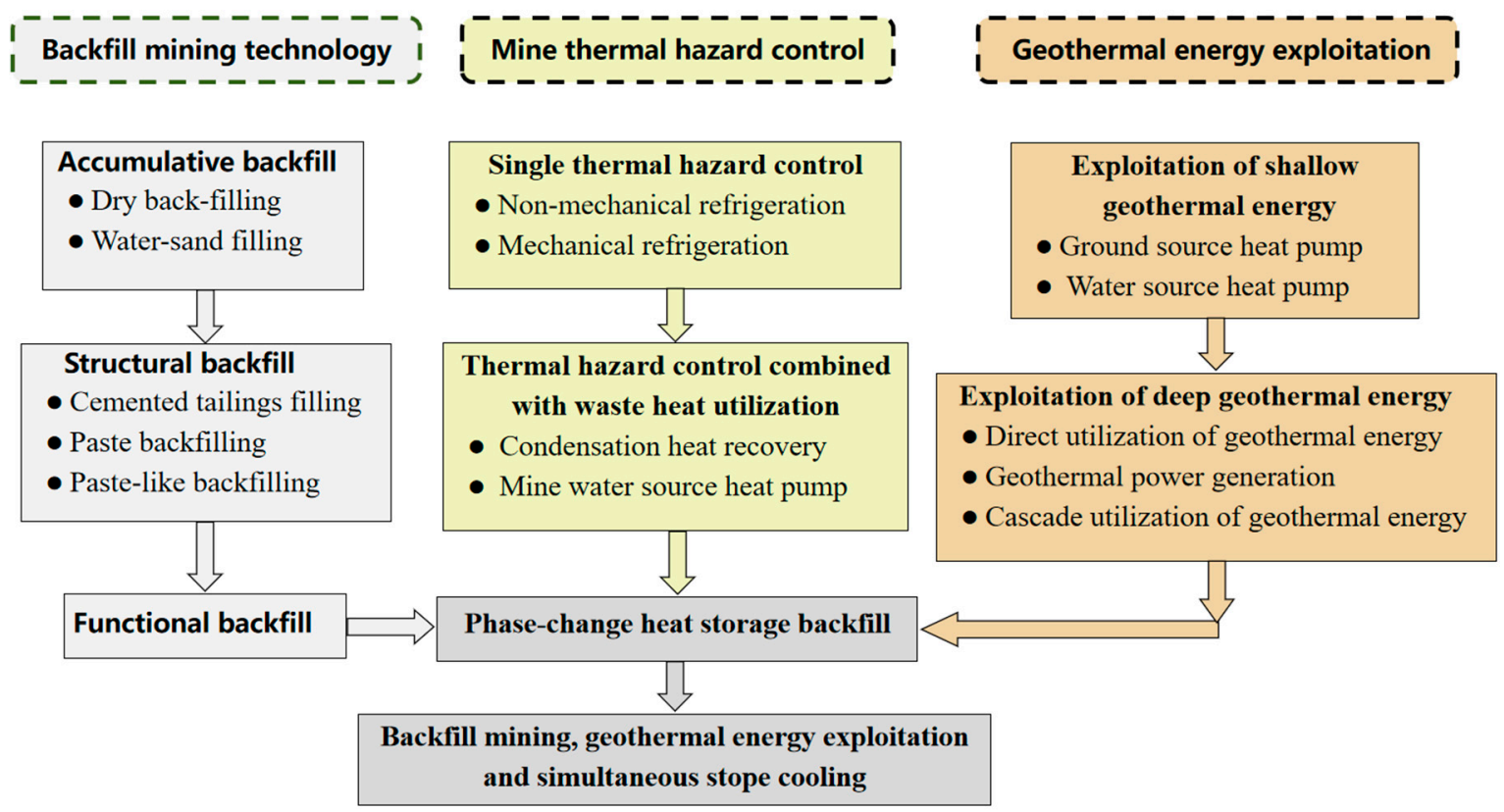

Figure 1. The concept for the phase-change heat storage backfill.

As the core of backfill mining technology, backfill materials directly determine the quality of the backfill body, the cost of backfill mining, and the effect of controlling surface subsidence. Moreover, a phase-change heat storage backfill puts forth a new requirement for backfill materials, i.e., when a certain dosage of PCM is added into backfill material, the flow characteristics of backfill slurry must meet the requirements of pipeline transportation for backfill mining. The backfill body formed by solidified backfill slurry also should have good mechanical strength required by backfill mining and good thermal properties required by geothermal energy exploitation.

Shape-stabilized PCMs can overcome negative influence caused by seepage or large volume changes during the solid-liquid and solid-gas phase-change. It does not need encapsulation as it increases the safety of material, reduces the heat transfer resistance of container, and is more conducive to heat transfer [29]. Shape-stabilized PCM is composed of a carrier substrate (supporting material) and phase-change medium. The carrier substrate can maintain the stability of the shape and physicochemical properties in the phase-change process of PCM, and has good thermal conductivity and mechanical properties, which can carry and limit the leakage of liquid PCMs [29,30]. The relevant research shows that tailings, fly ash, and waste rocks contained in backfill material can provide a carrier substrate for shape-stabilized PCMs [31,32], as they provide good conditions for implementing phase-change heat storage backfill technology.

According to the predetermined proportion, during the phase-change heat storage backfill process tailings, fly ash, waste rocks (or other aggregates), cementing materials, additive agents, and PCM are mixed with water and stirred to form a homogeneous backfill slurry. Then, the backfill slurry is transported via pipeline and poured into goaf, in which the cold fluid in the heat transfer tube is prearranged. Finally, the phase-change heat storage backfill body with inner buried tube is formed by solidified backfill slurry. The working process of the backfill body is shown in Figure 2 . 
During the of heat storage process, the backfill body absorbs heat from surrounding rock and airflow in stopes. The temperature increases when the phase-change temperature is reached and PCM melts. Then, the temperature of the backfill body continually increases near surrounding rock. Heat is collected and stored in the backfill body by means of sensible and latent heat. In this case, due to the heat absorption of the backfill body from the surrounding rock and airflow, this reduced heat release and so stope cooling was simultaneously realized. During the heat release process, the heat transfer tube is filled with cold fluid, the backfill body releases the heat stored in itself to cold fluid, and the temperature decreases. PCM solidifies after losing heat and then the backfill body temperature continually decreases near the cold fluid. This provides the conditions of sustainable collection for geothermal energy.

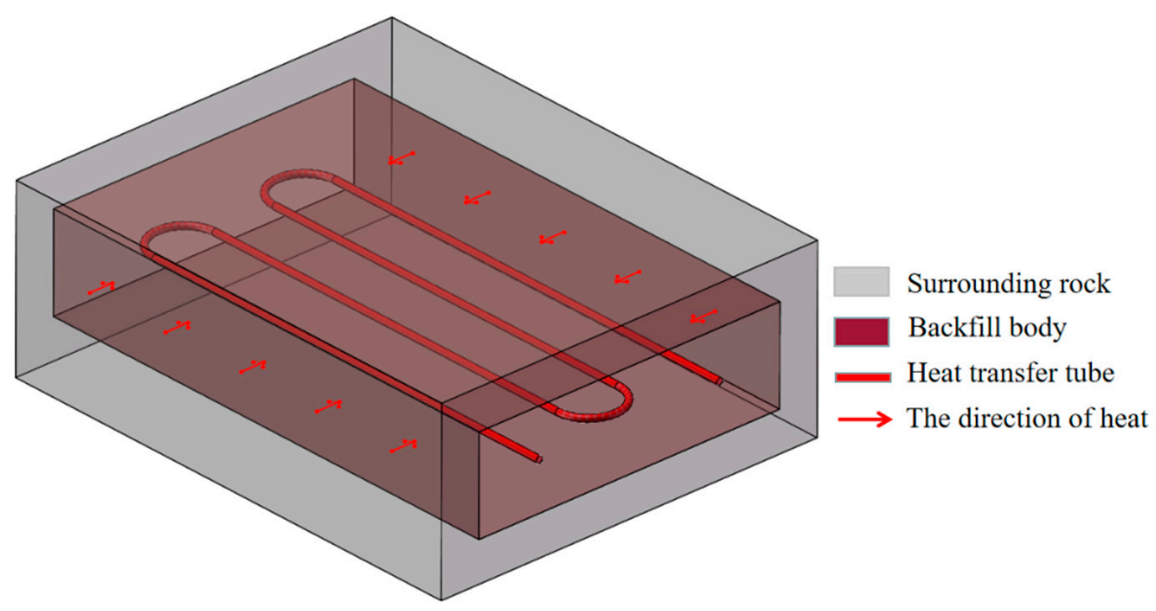

(a) Heat storage process

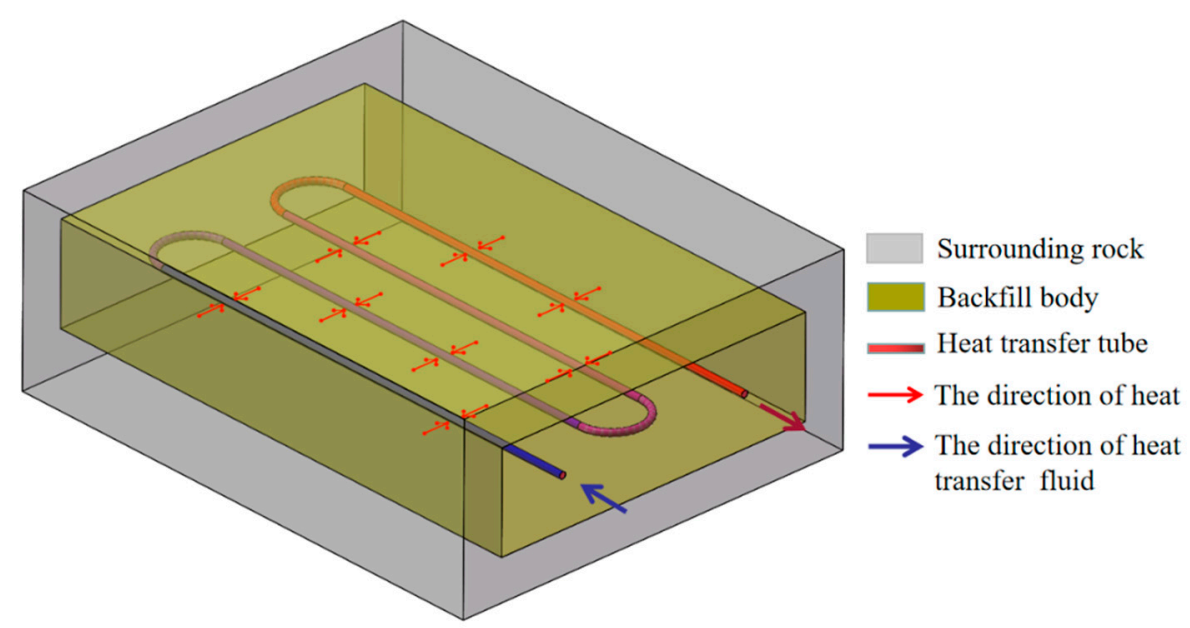

(b) Heat release process

Figure 2. The working process of the phase-change heat storage backfill body.

\section{The Technical System of Phase-Change Heat Storage Backfill}

\subsection{The Construction of Technical System}

Backfill mining involves pouring backfill slurry into a goaf. The backfill slurry then solidifies to form a cemented backfill body, which can control ground stress, as well as reduce, delay, and prevent the destruction and movement of surrounding rock after mining. Further, it can prevent surface subsidence. In preparation of backfill slurry, it is important to make use of solid wastes in order to realize green mining. Moreover, it is necessary to add a certain dosage of PCM into backfill material 
and to prearrange the heat transfer tube in the backfilled region. The backfill body has good thermal properties while meeting the requirements of mechanical strength for backfill mining. The extraction and utilization of geothermal energy can be realized by heat storage/heat release of the backfill body and cold fluid circulation. Therefore, the technical system of phase-change heat storage backfill involves optimized backfill slurry proportions added with PCM. The collaborative optimization for mechanical and thermal properties of the backfill body has mutual cooperation for backfill mining, geothermal energy exploitation, and simultaneous stope cooling.

In different mines, the geological conditions and ore body characteristics are different. The characteristics of geothermal temperature and ground stress are different with mining depth. Therefore, the types of solid wastes, PCM selections, and requirements of mechanical properties for backfill body are different. The backfill body is placed in high ground stress and high ground temperature environment in the deep mine. The complexity of the geological and ore body occurring in the mine has a diversity of solid wastes and PCMs and ground temperature and pressure variability. Moreover, there is an expansion and contraction of volume, and change of pore structure and seepage flow that occurs in the backfill body. All of these directly affect each segment of the technical system for phase-change heat storage backfill. These influencing factors have a complex relationship, mutual influence, and mutual restraint with the proportion of backfill materials, the mechanical/thermal properties, and the heat storage/heat release characteristics of the backfill body. The technical system for the phase-change heat storage backfill is shown in Figure 3.

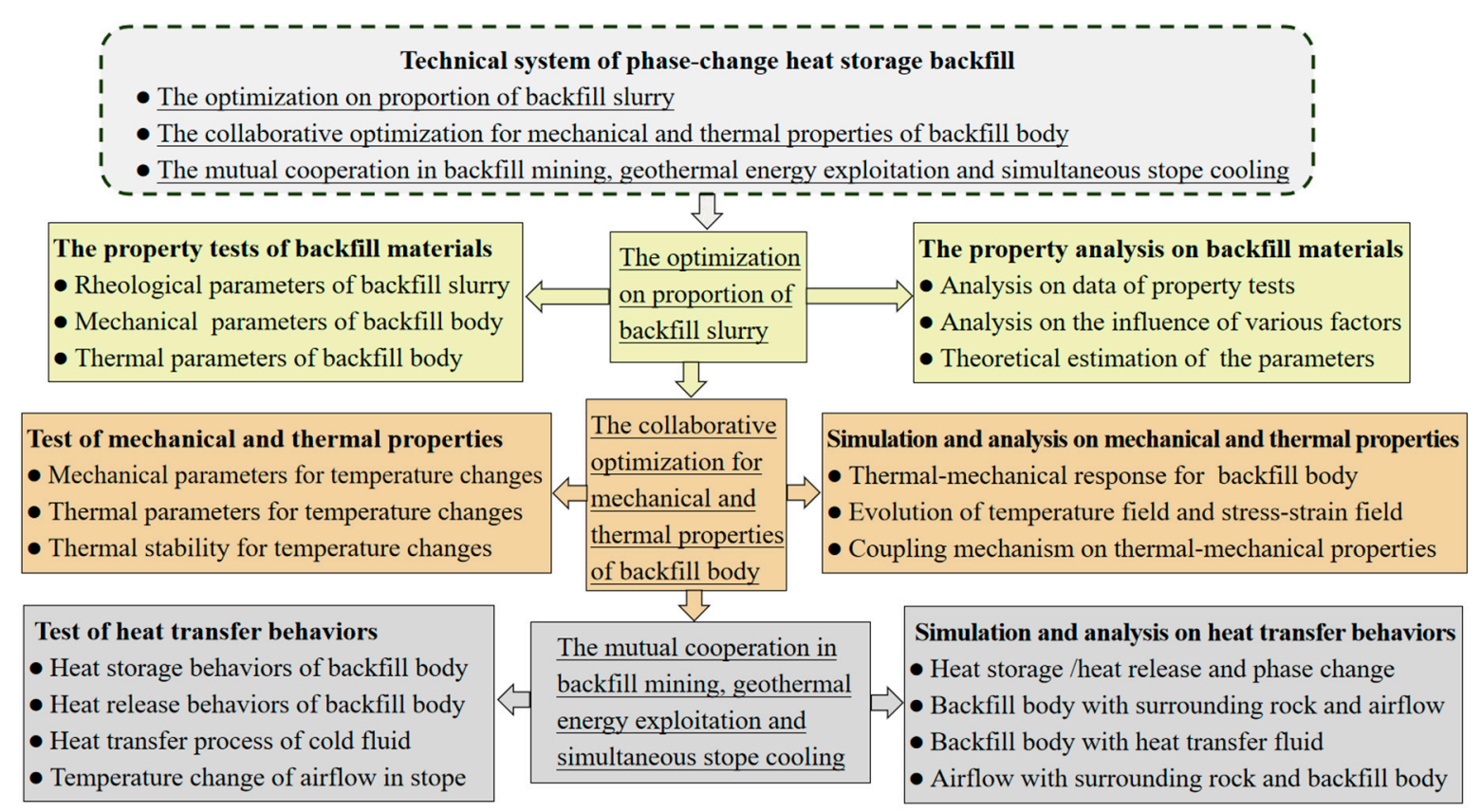

Figure 3. The technical system for phase-change heat storage backfill.

\subsection{The Optimized Proportion of Backfill Slurry}

Mining gradually develops to the deep layer. It is the goal of backfill mining technology to reduce backfill cost and ensure mining safety. The proportion of backfill slurry directly affects the mechanical and thermal properties of the backfill body, as well as the cost of backfill mining. Considering the specific conditions of various mines, making full use of solid wastes, selecting the heat storage materials with a suitable phase-change temperature, selecting for good comprehensive performance, determining the optimal proportion, preparing the backfill slurry with flow characteristics that meet the requirements of pipeline transportation, and forming a backfill body with mechanical strength that meets the requirements of backfill mining technology with good heat storage/heat release 
characteristics that meet the requirements of geothermal energy exploitation. All of the aforementioned qualities are important parts of phase-change heat storage backfill technology.

When preparing backfill slurry, solid wastes are selected-e.g., tailings, fly ash, waste rocks, coal gangue, slag, etc. [33,34] — and there are many types of heat storage materials available. Shape-stabilized PCMs are the main choice for heat storage materials, as their supporting materials mainly include cross linked high-polymer resin materials, porous inorganic materials, and inorganic nanomaterials. Phase-change mediums typically use solid-liquid PCMs with a high latent heat and nearly constant phase-change temperature, such as paraffin, fatty acids, high aliphatic hydrocarbons, esters, and polybasic alcohol, all of which have been widely utilized in thermal energy storage [35,36]. When heat storage materials are added into backfill materials, PCMs are required to have good thermal properties-such as suitable phase-change temperature, high latent heat, high thermal conductivity, large specific heat capacity, phase-change reversible, and repeatable cycle-as well as good environmental and economic performance [37] (i.e., no toxicity, no combustion, no pollution, convenient source, and a low cost). Various types of shape-stabilized PCMs, such as microcapsules, inorganic porous matrix, polymer matrix, nanometer matrix, and a functional additive type, can be obtained by synthesizing PCM supporting materials via different preparation methods [38,39].

To determine the optimal proportion of backfill slurry, an orthogonal or uniform test can be selected to conduct the design and optimization on proportion. The rheological parameters of backfill slurry (i.e., yield stress, shear stress, viscosity, slump, diffusivity, and precipitation) and the mechanical and thermal parameters of the backfill body (i.e., such as compressive strength, density, specific heat capacity, and thermal conductivity) were obtained by experimental testing. Based on the experimental results, the composition and proportion of backfill materials, the types and dosage of PCMs, cement-sand ratio, and slurry concentration on the rheological properties of backfill slurry can be analyzed and theoretically discussed. The optimization proportion model can be established for backfill slurry. The theoretical estimation method for thermal properties can be developed for backfill materials according to experimental data. Backfill slurry proportion optimization is shown in Figure 4.

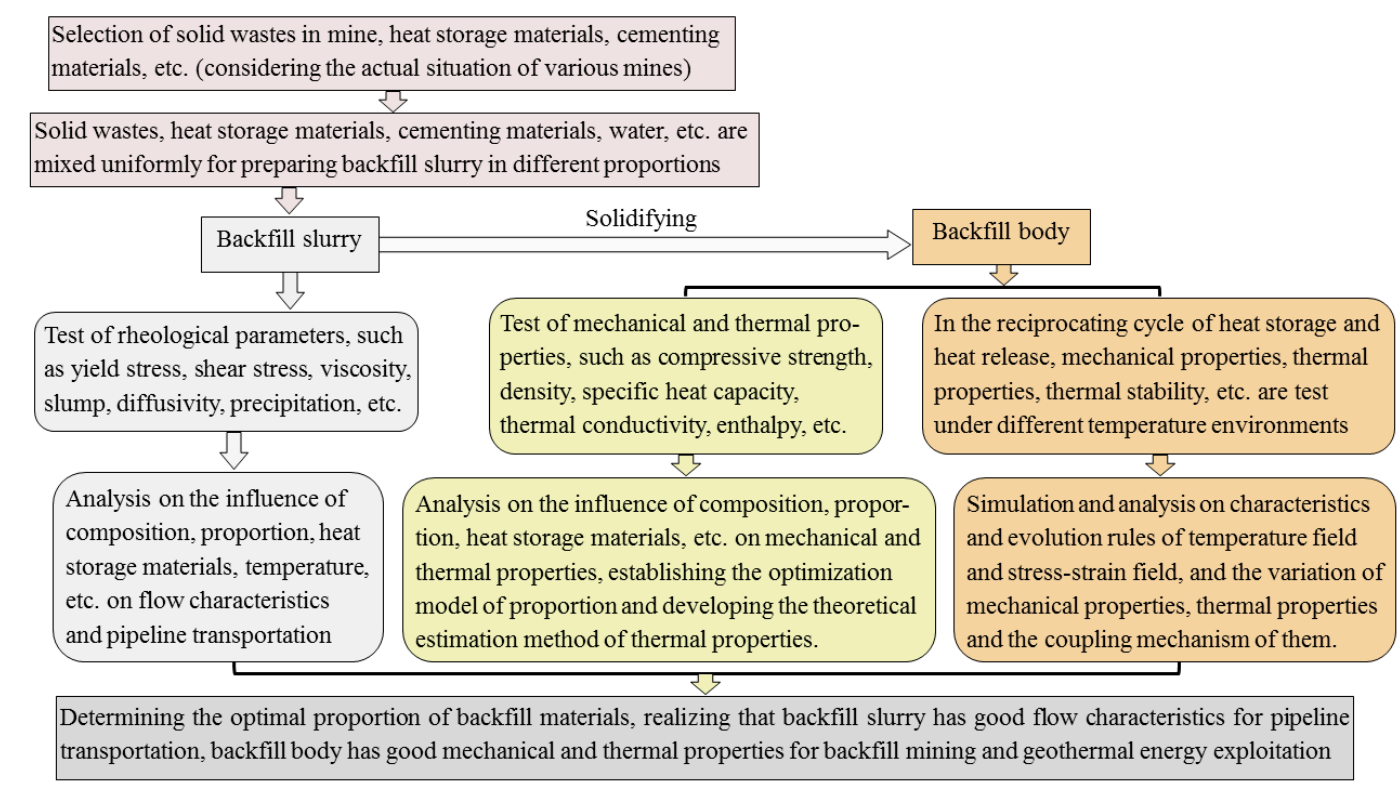

Figure 4. The optimized proportion of backfill slurry on mechanical and thermal properties of the backfill body.

\subsection{The Collaborative Optimization on Mechanical and Thermal Properties of the Backfill Body}

The technical system for a phase-change heat storage backfill should meet the requirements of mechanical properties for the backfill body (e.g., compressive strength) in order to control ground 
pressure, support surrounding rocks, and prevent surface subsidence. Yet it should also meet the requirements of thermal properties for the backfill body (i.e., specific heat capacity, thermal conductivity, and enthalpy) in order to gather, store, and extract geothermal energy. Thermal properties of the backfill body can be improved by adding PCMs into backfill materials, while mechanical strength can be weakened when adding PCMs [40]. Therefore, it is important to test and analyze the mechanical and thermal parameters of the backfill body with different materials, proportions, and PCMs dosages to obtain the appropriate PCM dosage.

When preparing backfill slurry, solid wastes and PCMs can be selected. Moreover, due to the influence of backfill materials, PCM types and dosages, cement-sand ratio, and slurry concentration, phase-change heat storage backfill bodies can be formed via a solidified backfill slurry. As such, their mechanical and thermal properties are quite different as they meet the technical requirements of backfill mining and geothermal energy exploitation under various conditions. When the backfill body is placed in the high pressure and temperature deep mining environment, it not only needs to finish heat storage and heat release through temperature variation and a PCM phase-change cycle to realize the continuous exploitation and utilization of geothermal energy, but it also needs to maintain its mechanical strength to control ground pressure and support surrounding rocks during temperature variation and PCM phase-change. During the continuous of heat storage process, the backfill body temperature gradually increases and PCM absorbs heat and melts, leading to a decrease in the backfill body's mechanical strength, which affects the backfill body's supporting role on stope. Therefore, it is necessary to test and analyze the mechanical and thermal properties of the backfill body during its temperature variation and phase-change.

During the heat storage and heat release cycle under different temperature environments, the mechanical properties, thermal properties, and thermal stability of the backfill body with different materials and proportions need to be experimentally tested and theoretically analyzed. Moreover, a thermal-mechanical response model for phase-change heat storage also needs to be established. The characteristics and evolutionary rules of the temperature field and stress-strain field need to be revealed using numerical simulation, and the variation in mechanical properties, thermal properties and the coupling mechanism on the backfill body's thermal-mechanical properties needs to be obtained. Through our tests, simulations, and analyses, the backfill body can meet the requirements of mechanical properties for controlling ground pressure and maintaining good thermal properties for geothermal energy exploitation under thermal behavior. It can not only provide basic data for collaborative optimization on mechanical and thermal properties but also provide theoretical reference for the optimized proportion of backfill slurry. This is because the backfill body with good mechanical and thermal properties is an important objective of the optimized proportion of backfill slurry. The backfill body's collaborative optimization on mechanical and thermal properties is shown in Figure 4.

\subsection{The Mutual Cooperation on Backfill Mining, Geothermal Energy Exploitation, and Simultaneous Stope Cooling}

In the backfill mining, the heat transfer tube for geothermal energy exploitation is prearranged in the backfill body, as shown in Figure 2. During the heat storage process, the backfill body absorbs heat from surrounding rocks and stope airflow, the temperature increases, and the heat is stored in the backfill body via sensible heat and latent heat. In this case, stope cooling is simultaneously realized. During the heat release process, the cold fluid absorbs heat from a backfill body during temperature difference. The backfill body releases the stored heat to cold fluid and the temperature decreases. The backfill body accumulates and stores heat via the heat storage process and transfers the stored heat to cold fluid through the heat release process [41]. Cold fluid obtains heat and the temperature increases. Fluid heat can be extracted and utilized using a heat pump unit to realize the collaboration between backfill mining and geothermal energy exploitation.

The thermal behavior of the backfill body mainly includes the convective heat transfer with airflow and cold fluid, as well as heat conduction between the backfill body and surrounding rock, and heat 
conduction and phase-change heat transfer. Therefore, the stope airflow, geometric parameters, heat transfer tube arrangement, cold fluid temperature/flow characteristics, surrounding rock temperature, and the thermal properties of backfill material all have an influence on heat transfer. The heat transfer model for the backfill body should be constructed under the influence of multiple factors. Three-dimensional unsteady heat conduction, convective heat transfer, and phase-change heat transfer involved in them should be studied via numerical simulation and an experimental test. According to our simulation and test results, the heat transfer mechanism in the backfill body, surrounding rock, airflow, and cold fluid can be revealed. The influence of surrounding rock, airflow, cold fluid, and thermal properties on heat storage/heat release behavior can be analyzed and discussed. This can provide a theoretical basis when studying the thermal control system of "backfill mining-geothermal energy exploitation-simultaneous stope cooling". The mutual cooperation of the three aspects is shown in Figure 5.

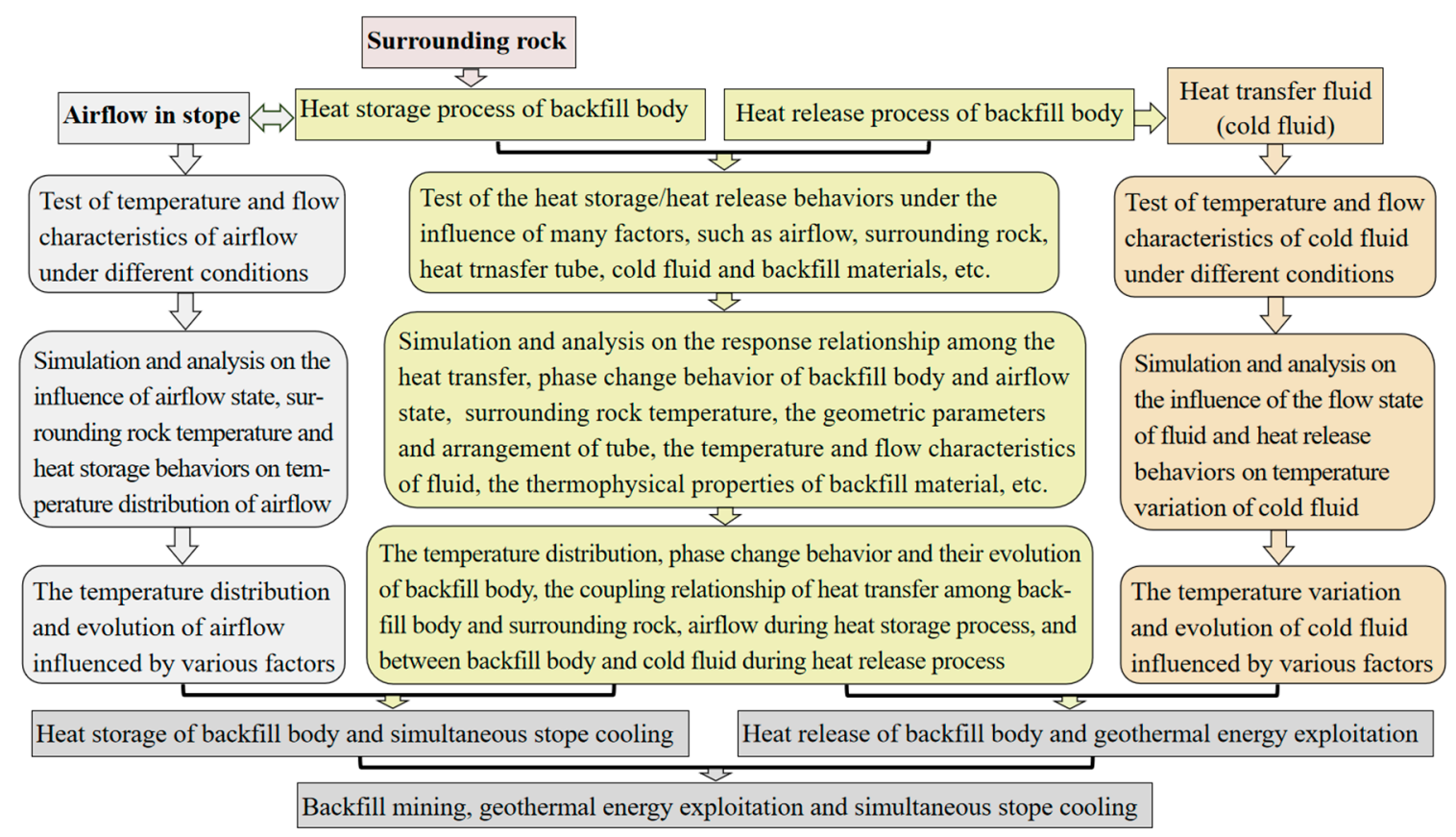

Figure 5. The mutual cooperation on backfill mining, geothermal energy exploitation and simultaneous stope cooling.

\section{The Heat Transfer Analysis of a Phase-Change Heat Storage Backfill}

The heat transfer behavior of the backfill body plays a key role in geothermal energy exploitation and stope cooling. It is the core of the phase-change heat storage backfill, which includes heat transfer among the backfill body, surrounding rock, and airflow during the heat storage process and heat transfer between the backfill body and cold fluid. During the heat release process, the phase-change heat transfer is in the backfill body.

\subsection{The Heat Storage/Heat Release Model of the Backfill Body}

During backfill mining, backfill slurry mixed with PCM is transported to a deep stope through a pipeline, solidifies to form the backfill body, and the cold fluid in the heat transfer tube is prearranged inside the backfill body. In the case of stratified backfill mining, mining is done layer by layer, and the backfill also is done layer by layer. The layers of the backfill body are divided into three cases: the top layer adjoins with stope, its upper surface absorbs heat from airflow by convection heat transfer, the bottom layer adjoins with surrounding rock, several intermediate layers are located between the top and the bottom layers, the sides of all layers adjoin with the surrounding rock, and the bottom and the sides both can absorb heat from surrounding rock. In describing the heat transfer problem, 
the physical model is shown in Figure 6. During the heat storage process, the backfill body absorbs heat from surrounding rocks through heat conduction, which can reduce heat dissipation from surrounding rocks to airflow, and absorbs the heat from airflow in stope through convection heat transfer, so as to decrease airflow temperature of airflow, i.e., realize simultaneous stope cooling. During the heat release process, the backfill body transfers the stored heat to cold fluid. There are complex three-dimensional unsteady heat transfer processes among the backfill body, surrounding rocks, and airflow. Moreover, phase-change heat transfer exists in the backfill body. In order to simplify the calculation, the following assumptions are made:

* The backfill body is a homogeneous and isotropic solid, and the thermophysical parameters remain constant.

* The backfill body is a porous medium with constant porosity, and all phases are in local thermodynamic equilibrium.

* During the heat storage process, the influences of the heat transfer tube and cold fluid are ignored.

* During the heat release process, there is no heat transfer in the backfill body to surrounding rocks and airflow.

- During the heat release process, the heat transfer along the axial direction of the heat transfer tube is ignored, and the heat transfer of the backfill body is a two-dimensional unsteady heat conduction.

* The contact thermal resistance between the backfill body and heat transfer tube is ignored.

* In a given temperature range, PCM only undergoes a solid-liquid phase-change, without supercooling and performance degradation.

* We did not consider the natural convection heat transfer of liquid PCM.

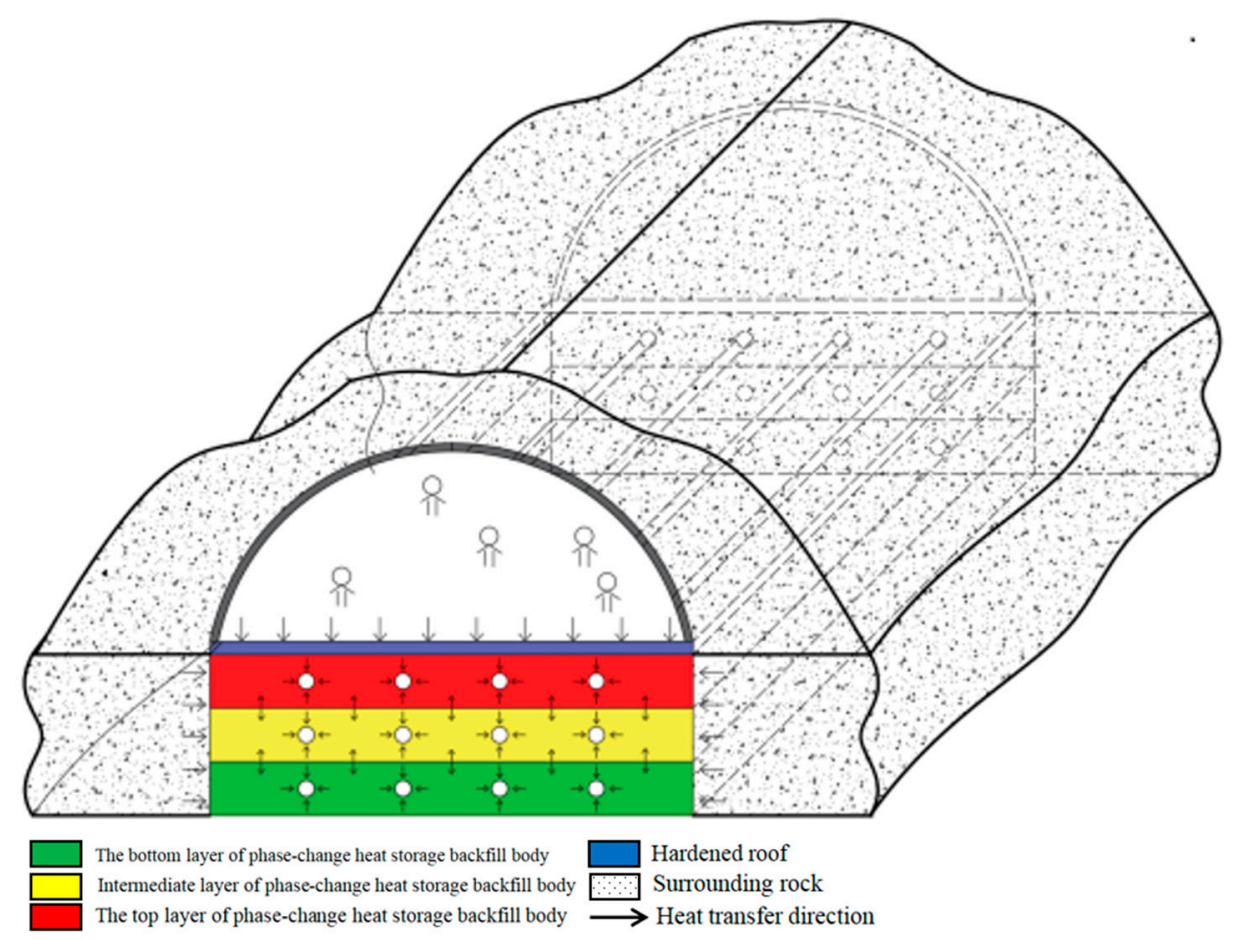

Figure 6. The physical model of the phase-change heat storage backfill body.

4.1.1. The Mathematical Model of the Backfill Body during the Heat Storage Process

The control equation for the backfill body during the heat storage process is shown as follows:

$$
\lambda\left(\frac{\partial^{2} T}{\partial x^{2}}+\frac{\partial^{2} T}{\partial y^{2}}+\frac{\partial^{2} T}{\partial z^{2}}\right)=\rho \frac{\partial h}{\partial \tau}
$$


the initial condition: $\left.T(x, y, z, \tau)\right|_{\tau=0}=T_{\text {ini }}$

the boundary condition of surrounding rocks: $T_{s}(x, y, z, \tau)=T_{b}$

the boundary condition of stope: $-\lambda\left(\frac{\partial T}{\partial n}\right)_{w}=h_{a f}\left(T_{w}-T_{a f}\right)$

where $T$ is the temperature $\left({ }^{\circ} \mathrm{C}\right) ; H$ is the total enthalpy equal to the sum of sensible and latent heat in the backfill body $(\mathrm{kJ} / \mathrm{kg}) ; \lambda$ is the thermal conductivity $\left(\mathrm{W} /\left(\mathrm{m} .{ }^{\circ} \mathrm{C}\right)\right) ; \rho$ is the density $\left(\mathrm{kg} / \mathrm{m}^{3}\right) ; T_{\text {ini }}$ is the initial temperature of the backfill body at the beginning of heat storage $\left({ }^{\circ} \mathrm{C}\right) ; h$ is the convection heat transfer coefficient $\left(\mathrm{W} /\left(\mathrm{m}^{2} .{ }^{\circ} \mathrm{C}\right)\right)$. The subscript $s$ expresses the boundary between the backfill body and surrounding rocks, $w$ expresses the boundary between the backfill body and stope, and af expresses airflow. $n$ is the normal direction of $w ; T_{b}$ is the temperature of surrounding rock at the boundary $s\left({ }^{\circ} \mathrm{C}\right) ; T_{w}$ is the temperature of the backfill body at the boundary $w,\left({ }^{\circ} \mathrm{C}\right)$.

\subsubsection{The Mathematical Model of the Backfill Body during the Heat Release Process}

For the complex three-dimensional unsteady heat transfer between the backfill body and cold fluid, the heat transfer models at different directions can solve the problem. The axial one-dimensional heat transfer model is established for cold fluid and the two-dimensional heat transfer model perpendicular to the heat transfer tube is established for the backfill body for the acting region of cold fluid. The heat transfer between cold fluid at the axial direction of the heat transfer tube and its surrounding backfill body can be calculated. The heat transfer coupling between the two regions can be realized.

(1) The axial one-dimensional heat transfer model for cold fluid.

We take the micro-segment of the heat transfer tube, $\Delta x$, as the object of study, according to the energy balance:

$$
T_{c f, \text { out }}=T_{c f, \text { in }}+\Delta x \times q_{x} /\left(C_{c f} m\right)
$$

where $q_{x}$ is the heat transfer capacity of unit length heat transfer tube $(\mathrm{W} / \mathrm{m}) ; m$ is the mass flow of cold fluid $(\mathrm{kg} / \mathrm{s})$; and $c$ is the specific heat capacity at constant pressure $\left(\mathrm{J} /\left(\mathrm{kg} .{ }^{\circ} \mathrm{C}\right)\right)$. The subscript $c f$ expresses cold fluid; in expresses inlet; out expresses outlet.

(2) The two-dimensional heat transfer model on the plane perpendicular to the heat transfer tube for the backfill body.

$$
\lambda\left(\frac{\partial^{2} T}{\partial y^{2}}+\frac{\partial^{2} T}{\partial z^{2}}\right)=\rho \frac{\partial T}{\partial \tau}
$$

the initial condition: $T_{c f}=T_{p}=T_{b f}=T_{i n i}$

the boundary condition:

(1) the boundary condition of the cold fluid's acting region: $q_{l}=0$

(2) the boundary condition of the contact surface for the outer wall of the heat transfer tube and backfill body: $T_{p}=T_{b f}, q_{p}=q_{b f}$

(3) the boundary condition of the cold fluid inlet: $\left.T_{c f}(x, \tau)\right|_{x=0}=T_{c f, i n}(\tau)$

(4) the boundary condition of the contact surface for the heat transfer tube's inner wall and cold fluid:

$$
-\lambda \frac{\partial T_{b f}}{\partial n}=h_{c f}\left(T_{c f}-T_{b f}\right)
$$

where $T_{\text {ini }}$ is the initial temperature of the backfill body at the beginning of heat release $\left({ }^{\circ} \mathrm{C}\right) ; q$ is the heat flux density $\left(\mathrm{W} / \mathrm{m}^{2}\right) ; n$ is the normal direction of the contact surface for the outer wall of the heat transfer tube and backfill body. The subscript bf expresses the backfill body, $p$ expresses the wall of the heat transfer tube, and $l$ expresses the acting region boundary of cold fluid on the plane perpendicular to the heat transfer tube. 


\subsection{The Phase-Change Heat Transfer Model for the Backfill Body}

In this study, the backfill body formed by a solidified backfill slurry, which was added with a certain dosage of PCM and uniformly mixed. It was regarded as a porous medium. In the numerical simulation, the phase-change mechanism of the backfill body during the heat storage process/heat release was analyzed based on the enthalpy-porosity method. The heat balance between PCM and a solid aggregate of the backfill body was divided into local thermal equilibrium and non-local thermal equilibrium. Based on the assumptions made in Section 4.1, the natural convection heat transfer of liquid PCM was not considered, so local thermal equilibrium model was adopted. The expression is shown as follows [42,43]:

$$
(\rho c)_{e f f} \frac{\partial T_{e f f}}{\partial t}=\lambda_{e f f}\left(\frac{\partial^{2} T_{e f f}}{\partial x^{2}}+\frac{\partial^{2} T_{e f f}}{\partial y^{2}}+\frac{\partial^{2} T_{e f f}}{\partial z^{2}}\right)+\rho_{p c m} L_{f} \varepsilon \frac{\partial \gamma}{\partial \tau}
$$

The parameters in Equation (4) are expressed as follows:

$$
\begin{gathered}
(\rho c)_{e f f}=(1-\varepsilon)(\rho c)_{b f s}+\varepsilon(\rho c)_{p c m} \\
(\rho c)_{p c m}=\gamma(\rho c)_{p c m, l}+(1-\gamma)(\rho c)_{p c m, s} \\
\lambda_{e f f}=\varepsilon \lambda_{p c m}+(1-\varepsilon) \lambda_{b f s} \\
\lambda_{p c m}=\gamma \lambda_{p c m, l}+(1-\gamma) \lambda_{p c m, s}
\end{gathered}
$$

where $\varepsilon$ is the porosity of the backfill body and is the volume fraction of PCM, \%; $L_{f}$ is the latent heat of $\mathrm{PCM}, \mathrm{kJ} / \mathrm{kg}$. The subscript eff expresses equivalent; $b f s$ expresses the solid aggregate of the backfill body; $p c m$ expresses phase-change material; $l$ expresses the liquid phase of PCM; and $s$ expresses the solid phase of PCM. $\gamma$ is the liquid fraction of PCM, wherein the value depends on the temperature of the backfill body and can be expressed as follows:

$$
\gamma=\left\{\begin{array}{cc}
0 & T<T_{s} \\
T-T_{s} & T_{s}<T<T_{l} \\
T_{l}-T_{s} & T>T_{l} \\
1 &
\end{array}\right.
$$

where $T_{S}$ is the phase-change temperature of solid $\mathrm{PCM},{ }^{\circ} \mathrm{C} ; T_{l}$ is the phase-change temperature of liquid $\mathrm{PCM},{ }^{\circ} \mathrm{C}$.

The melting and solidification model of PCM is shown as follows:

The continuity equation:

$$
\frac{\partial \rho_{p c m}}{\partial \tau}+\nabla\left(\rho_{p c m} \vec{u}\right)=0
$$

The energy equation:

$$
\frac{\partial}{\partial \tau}\left(\rho_{p c m} H\right)+\nabla\left(\rho_{p c m} v_{i} H\right)=\nabla\left(\lambda_{p c m}\left(\nabla T_{e f f}\right)\right)+\frac{\rho_{p c m}}{c_{p c m}} \frac{\partial(\Delta H)}{\partial t}
$$

where $H$ is the enthalpy of PCM, i.e., the sum of sensible heat enthalpy and latent heat enthalpy $\Delta H$, $\mathrm{kJ} / \mathrm{kg} ; v_{i}$ is the flow velocity of liquid phase when phase-change occurs, $\mathrm{m} / \mathrm{s} ; \vec{u}$ is velocity vector.

\subsection{The Numerical Simulation on Heat Storage/Release Process for the Backfill Body}

\subsubsection{Grid Generation and Independence Verification}

According to the heat transfer characteristics of the backfill body, a three dimensional model was established using Solidworks Software and a grid was generated using ICEM Software (Figure 7). In the whole grid generation, the structural hexahedron was adopted for the backfill body and cold 
fluid. In order to reduce calculation error and enhance the heat transfer simulation between cold fluid and the backfill body, the cold fluid was divided by the inner O block, and the wall of the heat transfer tube and U-tube bending were encrypted. The simulation result was feasible when the U-tube bending was treated according to adiabatic condition, i.e., the energy change was ignored [44].

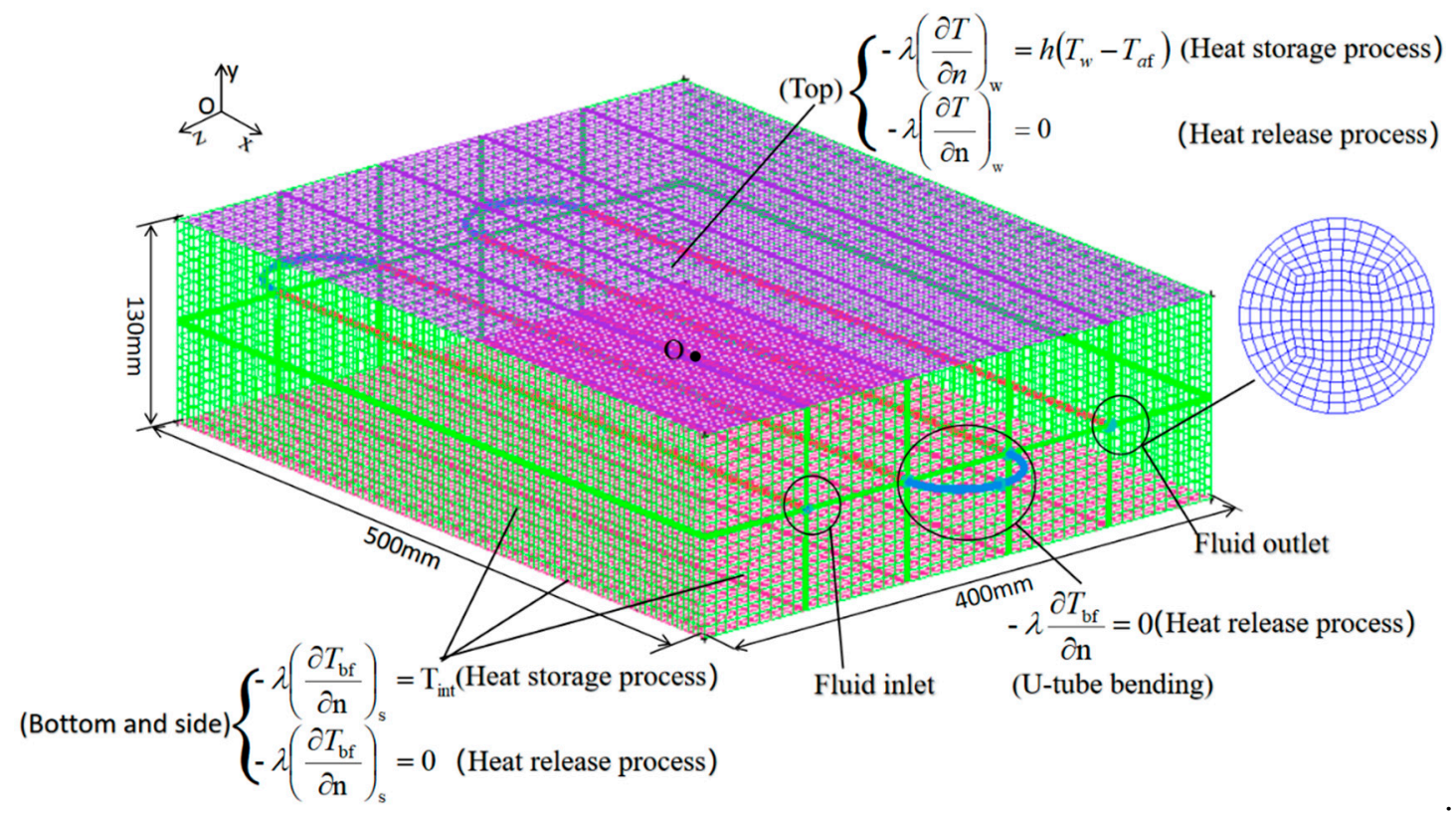

Figure 7. The grid generation for the backfill body.

In order to determine the optimal grid number and time step for numerical simulation, the average temperature of the backfill body and cold fluid outlet temperature were taken as the reference for heat storage and release, respectively. Numerical simulation was conducted over $5 \mathrm{~h}$. During the heat storage process, grid numbers were $0.1296,0.2176$, and 0.3563 million. During the heat release process, grid numbers were $0.2915,0.4656$, and 0.6886 million (Figures $8 \mathrm{a}$ and $9 \mathrm{a}$ ). Time step independence was determined by taking $1 \mathrm{~s}, 5 \mathrm{~s}$, and $10 \mathrm{~s}$, respectively (Figures $8 \mathrm{~b}$ and $9 \mathrm{~b}$ ). As can be seen, the grid number and time step had little effect on the simulation results, as the average temperature of the backfill body and cold fluid outlet temperature had no obvious difference in grid numbers or time steps. To ensure simulation result accuracy, we reduced calculation workload and improved calculation efficiency. Thus, grid numbers of 0.2176 million and 0.4656 million were adopted for heat storage and heat release. Further, a time step of $5 \mathrm{~s}$ were adopted for simulation. 


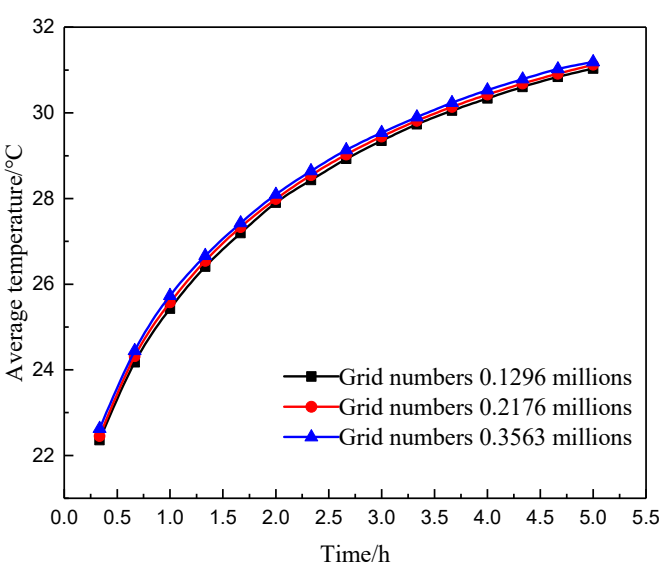

(a) Grid independency

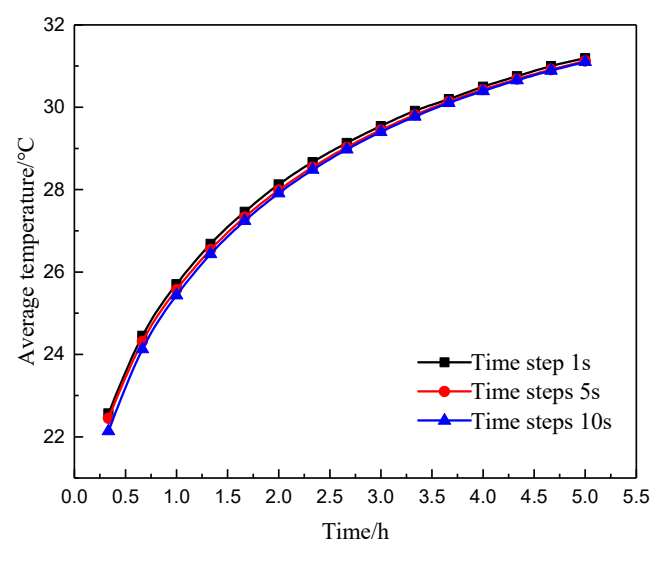

(b) Time step independency

Figure 8. The grid and time step independence for the heat storage process.

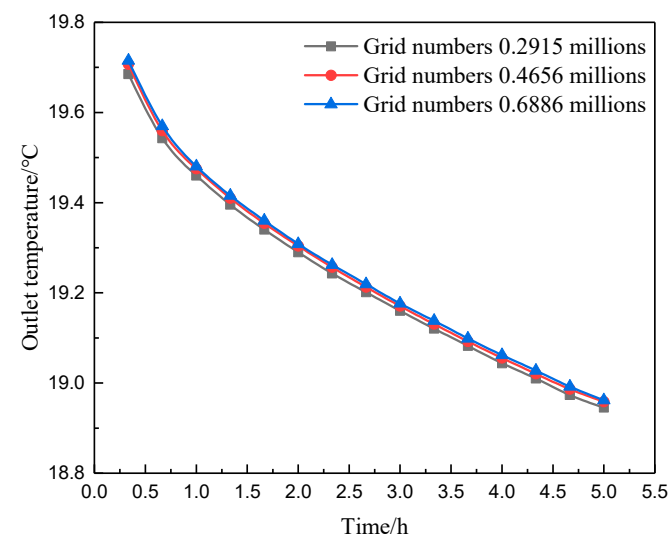

(a) Grid independency

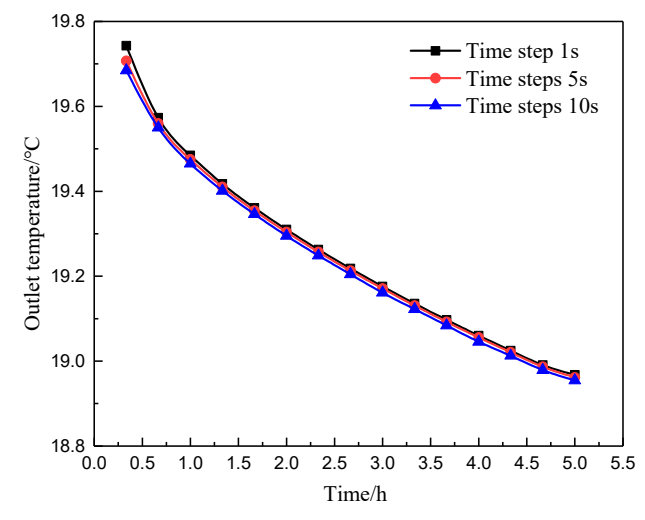

(b) Time step independency

Figure 9. The grid and time step independence for the heat release process.

\subsubsection{Setting Simulation Conditions}

As shown in Figure 7, the size of the backfill body was $500 \mathrm{~mm} \times 400 \mathrm{~mm} \times 130 \mathrm{~mm}$. Tailings of a metal mine were used as backfill aggregate. Paraffin microcapsules were selected as heat storage materials and uniformly mixed with backfill slurry (slurry concentration $=70 \%$; cement-sand ratio of 1:4; paraffin percentage $=5 \%$ (the volume fraction)). The thermophysical parameters of the backfill body were measured after curing for 28 days. The inner diameter of the heat transfer tube was $4 \mathrm{~mm}$ and the distance between the adjacent tube centers was $80 \mathrm{~mm}$. The initial temperature of the backfill body at the beginning of heat storage was $18^{\circ} \mathrm{C}$. The temperature of surrounding rocks at the boundary of the backfill body was $35^{\circ} \mathrm{C}$. The temperature was $26^{\circ} \mathrm{C}$ and velocity was $2 \mathrm{~m} / \mathrm{s}$ for airflow in stope. The calculated convective heat transfer coefficient on the surface of the backfill body near stope was $11.104 \mathrm{~W} /\left(\mathrm{m}^{2} \cdot{ }^{\circ} \mathrm{C}\right)$. The initial temperature of the backfill body at the beginning of heat release was $35^{\circ} \mathrm{C}$. The inlet temperature was $18^{\circ} \mathrm{C}$ and the inlet velocity was $0.2 \mathrm{~m} / \mathrm{s}$ for cold fluid. The thermophysical parameters of the backfill body, PCM, cold fluid, and heat transfer tube are shown in Table 1.

Table 1. The thermophysical parameters.

\begin{tabular}{|c|c|c|c|c|c|c|}
\hline Item & Material & $\begin{array}{l}\text { Density } \\
\left(\mathrm{kg} / \mathrm{m}^{3}\right)\end{array}$ & $\begin{array}{c}\text { Specific Heat Capacity } \\
(\mathrm{J} /(\mathrm{kg} \cdot \mathrm{K}))\end{array}$ & $\begin{array}{l}\text { Thermal Conductivity } \\
(\mathrm{W} /(\mathrm{m} \cdot \mathrm{K}))\end{array}$ & $\begin{array}{l}\text { Latent Heat } \\
(\mathrm{kJ} / \mathrm{kg})\end{array}$ & $\begin{array}{l}\text { Phase-Change Temperature } \\
\text { (K) }\end{array}$ \\
\hline Cold fluid & Water & 998.5 & 4185 & 0.594 & - & - \\
\hline Tube material & Polyethylene (PE) & 950 & 2100 & 0.46 & - & - \\
\hline PCM & RT28 & 790 & 2020 & 0.28 & 186 & $301 / 299$ \\
\hline Backfill body & - & 1682 & 1650 & 0.6936 & - & - \\
\hline
\end{tabular}




\subsubsection{Results and Analysis from the Heat Storage Process}

Figure 10 shows the temperature distribution on section $X=0$ of the backfill body at different heat storage times. It shows that the higher temperature region gradually expanded from the surrounding rocks to the interior of the backfill body. The expansion was faster in the early stage and gradually slowed in the later stage, leading to a continuous reduction in the lower temperature region. The temperature region of $T_{b f}=18{ }^{\circ} \mathrm{C}$ at the direction of $\mathrm{Z}$ reduced from $300 \mathrm{~mm}$ to $220 \mathrm{~mm}$ within $20 \mathrm{~min}-1 \mathrm{~h}$ (the decrement was $80 \mathrm{~mm}$ within $40 \mathrm{~min}$ ). It reduced to $140 \mathrm{~mm}$ within 1 to $2 \mathrm{~h}$ (the decrement was $80 \mathrm{~mm}$ within $1 \mathrm{~h}$ ) and then almost stayed at $100 \mathrm{~mm}$ within the following 3-5 h. The temperature region of $T_{b f}=18^{\circ} \mathrm{C}$ at the direction of $Y$ also reduced and gradually moved toward stope. It reduced from $70 \mathrm{~mm}$ to $40 \mathrm{~mm}$ within $20 \mathrm{~min}-1 \mathrm{~h}$ (the decrement was $30 \mathrm{~mm}$ within $40 \mathrm{~min}$ ) and reduced to $30 \mathrm{~mm}$ within 1-2 $\mathrm{h}$ (the decrement is $10 \mathrm{~mm}$ within $1 \mathrm{~h}$ ). In addition, there was a temperature region rise on the side near the stope. The backfill body absorbed heat from the airflow. Within the following 3-5 h, the temperature region $T_{b f}=18{ }^{\circ} \mathrm{C}$ at the direction of $Y$ reduced from $40 \mathrm{~mm}$ to $25 \mathrm{~mm}$ (the decrement is $15 \mathrm{~mm}$ within $2 \mathrm{~h}$ ), and the temperature region rise on the side near the stope disappeared, i.e., the backfill body no longer absorbed heat from airflow. Moreover, the temperature of the backfill body near the surrounding rocks was always higher than the adjacent stope. The influence of airflow on heat storage was less than the surrounding rock. Therefore, the heat transfer of surrounding rock was the main heat storage mode for the backfill body. The closer to the surrounding rock, the more obvious the temperature rise of the backfill body.

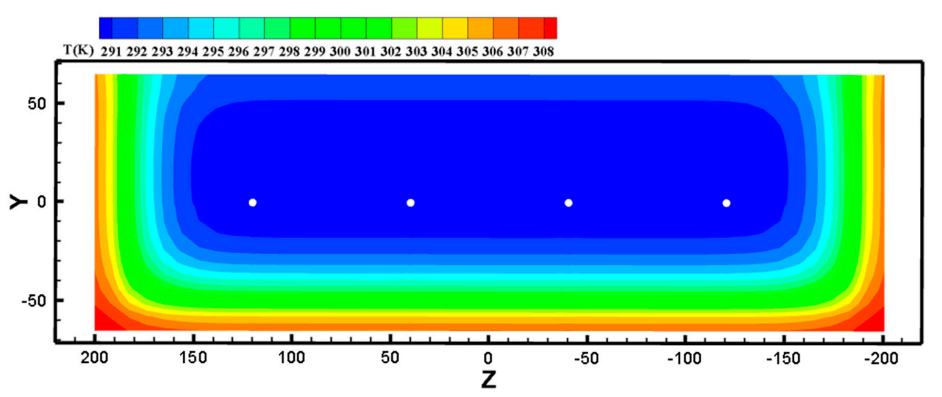

(a) $20 \mathrm{~min}$.

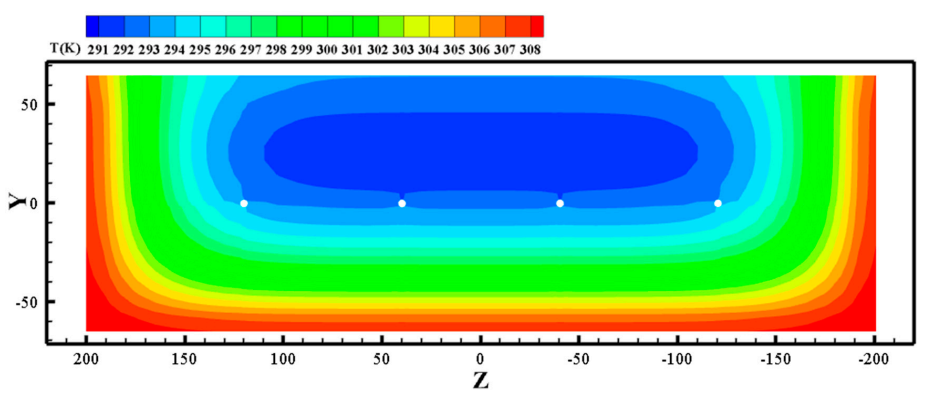

(b) $1 \mathrm{~h}$.

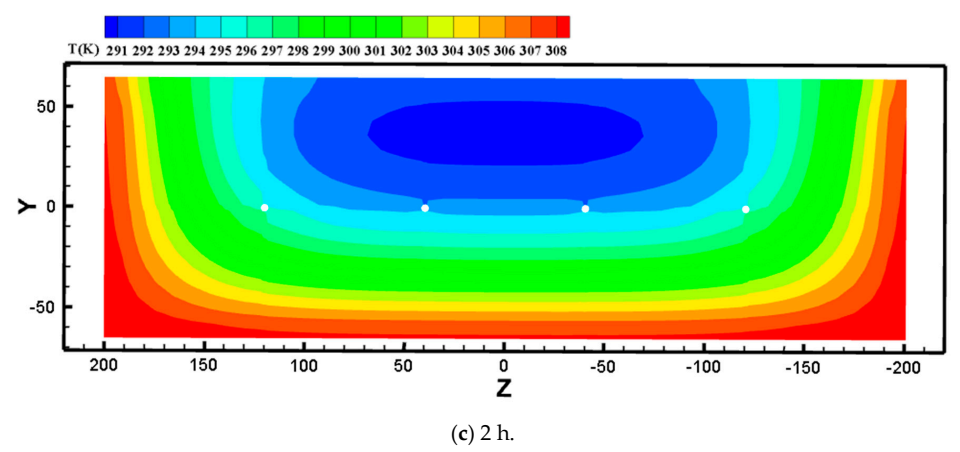

Figure 10. Cont. 


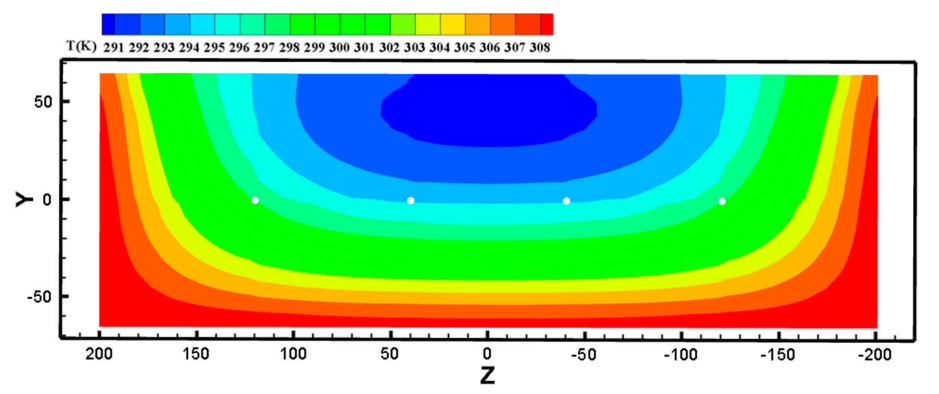

(d) $3 \mathrm{~h}$.

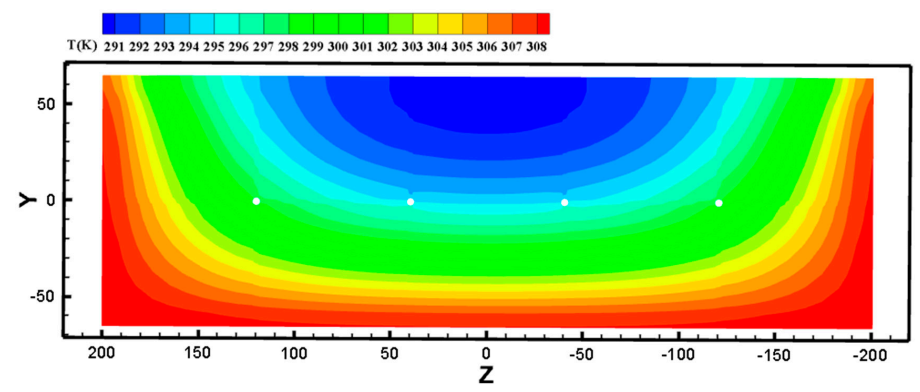

(e) 4 h.

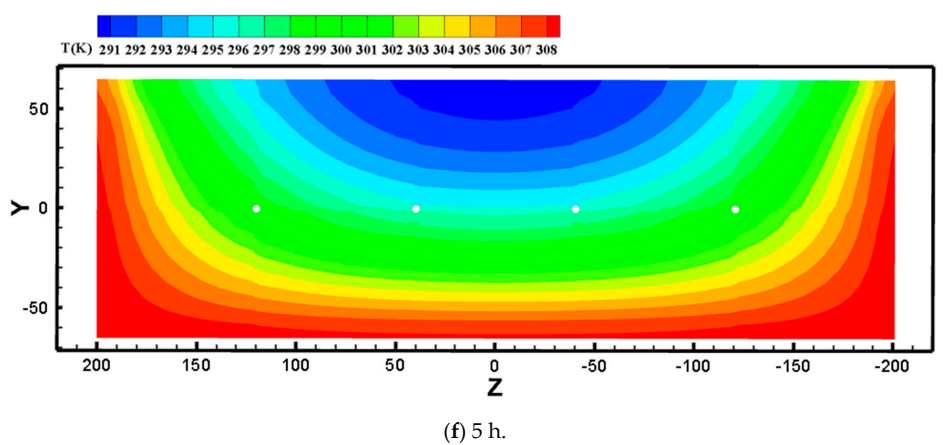

Figure 10. The temperature distribution of the backfill body during the heat storage process.

In the early stage of heat storage, the temperature difference of the backfill body with surrounding rocks and airflow was larger, and the heat transfer rate was higher. However, during the heat storage process, backfill body temperature gradually increased, temperature difference became smaller, and heat transfer rate gradually decreased. Therefore, the expansion of a higher temperature region was faster in the early stage and became slower in the late stage. Moreover, when the temperature of the backfill body was higher than the airflow, the backfill body no longer absorbed heat from airflow, resulting in the disappearance of the temperature rise region on the side near the stope.

\subsubsection{Results and Analysis from the Heat Release Process}

Figure 11 shows the temperature distribution for section $Y=0$ from the backfill body at different heat release times. The temperature of the backfill body in the heat transfer tube gradually decreased and the lower temperature region gradually expanded from the heat transfer tube to the periphery during heat release. Expansion was faster in the early stage and gradually slowed down in the late stage due to a temperature difference. The heat transfer rate was larger in the early stage, then gradually decreased. Figure 11 (Point $\mathrm{O}$ ) shows that the temperature was about $34.02{ }^{\circ} \mathrm{C}, 31.93{ }^{\circ} \mathrm{C}$, $30.17^{\circ} \mathrm{C}$, and $29.09^{\circ} \mathrm{C}$ at the heat release of $20 \mathrm{~min}, 1 \mathrm{~h}, 2 \mathrm{~h}$, and $3 \mathrm{~h}$, respectively. At the inlet of cold fluid, the temperature region of $T_{b f}=27.55^{\circ} \mathrm{C}$ around the heat transfer tube expanded from $1.5 \mathrm{~mm}$ to $18 \mathrm{~mm}$ within $20 \mathrm{~min}-2 \mathrm{~h}$ (the increment was $16.5 \mathrm{~mm}$ within $100 \mathrm{~min}$ ), and expanded from $18 \mathrm{~mm}$ to $27 \mathrm{~mm}$ within $2 \mathrm{~h}-5 \mathrm{~h}$ (the increment is $9 \mathrm{~mm}$ within $180 \mathrm{~min}$ ). 


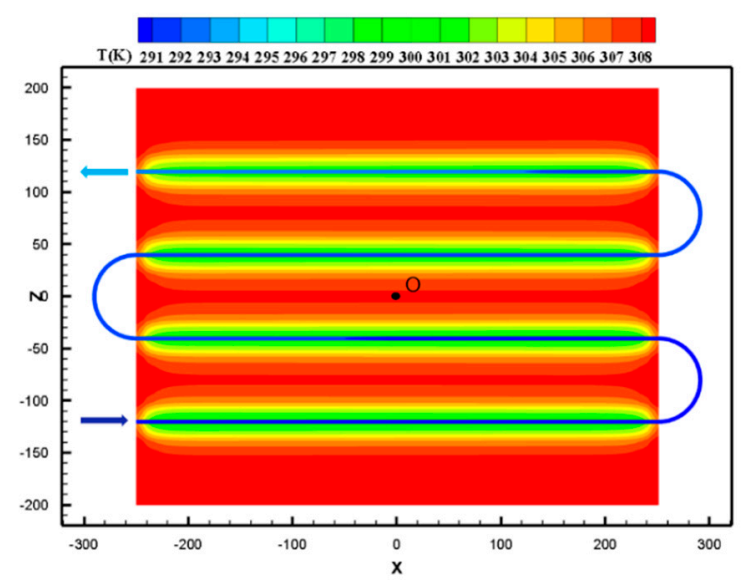

(a) $20 \mathrm{~min}$.

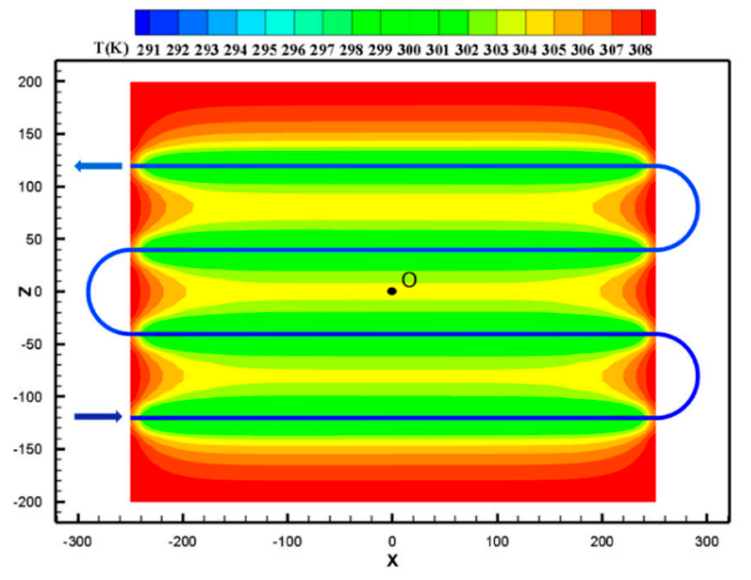

(c) $2 \mathrm{~h}$.

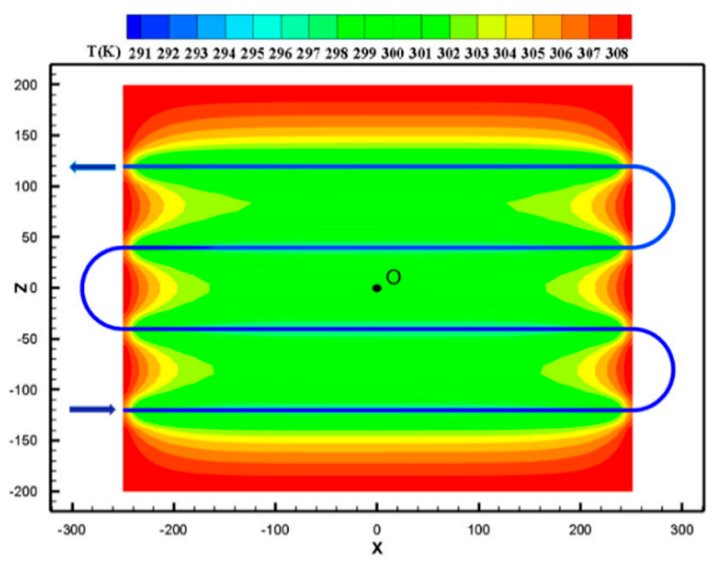

(e) $4 \mathrm{~h}$.

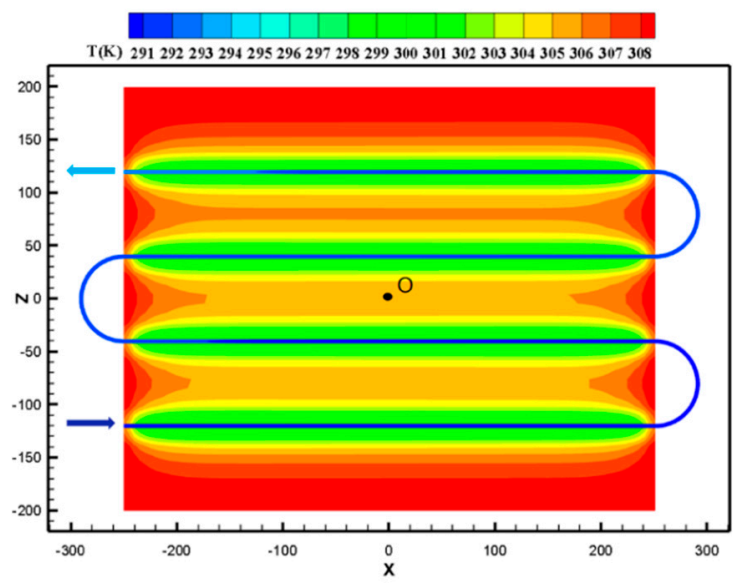

(b) $1 \mathrm{~h}$.

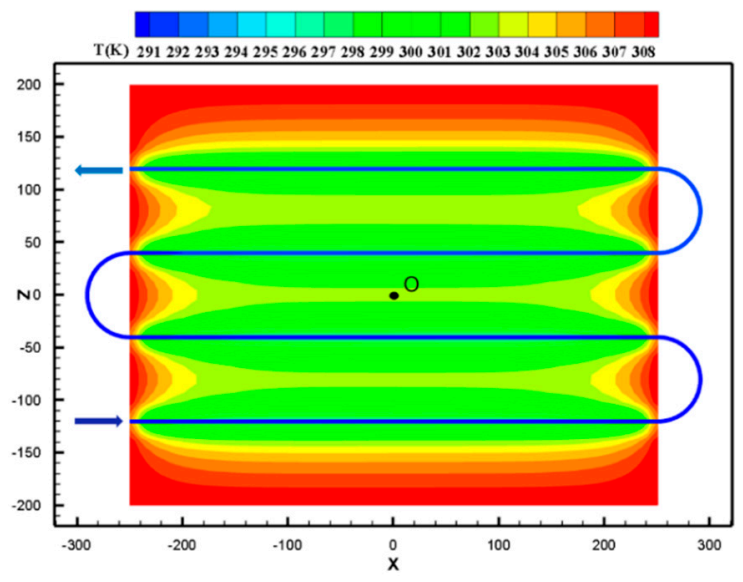

(d) $3 \mathrm{~h}$.

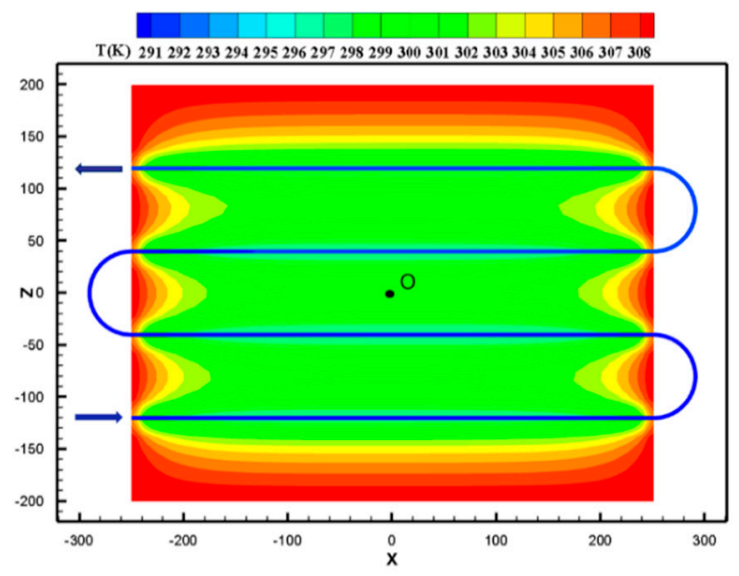

(f) $5 \mathrm{~h}$.

Figure 11. The temperature distribution of the backfill body during the heat release process.

Figure 11 shows that the lower temperature region was larger around the middle tubes than around the inlet and outlet tube at the same heat release time. This phenomenon gradually became obvious during the heat release process. At the heat release of $2 \mathrm{~h}$, the temperature region of $T_{b f}=28.5^{\circ} \mathrm{C}$ around the heat transfer tube was $17 \mathrm{~mm}, 21 \mathrm{~mm}, 18 \mathrm{~mm}$, and $13 \mathrm{~mm}$ along the cold fluid's flow direction. This was because the backfill body temperature in the middle tubes was affected by the cold fluid on both sides and there was an interactive heat release region. Thus, the lower temperature 
region around the middle tubes was larger. Moreover, the closer to the inlet the lower the cold fluid temperature, and the more obvious the heat release interaction was between tubes. At the heat release of $2 \mathrm{~h}$ (Figure 11c), the width of the temperature region of $T_{b f}=30^{\circ} \mathrm{C}$ between tubes (the yellow region) was $10 \mathrm{~mm}, 18 \mathrm{~mm}$, and $25 \mathrm{~mm}$ along the cold fluid's flow direction. The smaller the width of this region, the more obvious the heat release interaction between tubes was. Until the heat release of $5 \mathrm{~h}$, the temperature of most regions within the influence range was close to each other (about $27^{\circ} \mathrm{C}$ ). There was still a temperature difference between the backfill body and cold fluid, so the heat release continued.

\section{Conclusions}

(1) We investigated the technical system of a phase-change heat storage backfill. The main content involved an optimized proportion of backfill slurry added with phase-change materials (PCMs). There was collaborative optimization on the mechanical and thermal properties of the backfill body, and mutual cooperation on backfill mining, geothermal energy exploitation, and simultaneous stope cooling.

(2) The optimized proportion made backfill slurry with flow characteristics that met pipeline transportation requirements. The backfill body was formed by solidified backfill slurry and its mechanical strength met the requirements of backfill mining technology, with good heat storage/heat release characteristics that met the requirements of geothermal energy exploitation. The heat transfer behavior of the backfill body plays a key role in geothermal energy exploitation and stope cooling, and it is the core of the phase-change heat storage backfill system.

(3) We simulated the backfill body's heat storage process. The results showed that the higher temperature region gradually expanded from surrounding rocks to the interior of the backfill body, and the expansion was faster in the early stage and slower in the later stage. Moreover, the influence of the airflow on heat storage was obviously less than the surrounding rock. Therefore, the heat transfer of the surrounding rock was the main heat storage mode for the backfill body. However, the closer to the surrounding rock, the more obvious the temperature rise of the backfill body.

(4) We simulated the backfill body's heat release process. The results showed that the lower temperature region gradually expanded from the heat transfer tube to the periphery during the heat release process. The expansion was faster in the early stage and gradually slowed down in the late stage. The temperature of the backfill body around the middle tubes was affected by the cold fluid on both sides and there was an interaction region of heat release, so the lower temperature region around the middle tubes was larger. Moreover, the closer to the inlet, the more obvious the heat release interaction was between the tubes.

Author Contributions: Resources, Writing—Review \& Editing, X.Z.; Writing Original Draft, M.X.; Investigation, Formal analysis, L.L. (Li Liu); Conceptualization, Methodology, L.L. (Lang Liu); Supervision, Data Curation, M.W.; Validation, H.J.; Review \& Editing, K.-I.S. All authors have read and agreed to the published version of the manuscript.

Funding: This research was supported by the National Natural Science Foundation of China (Nos. 51974225, 51674188, 51874229, 51904224, 51904225, 51704229), Shaanxi Innovative Talents Cultivate Program-New-star Plan of Science and Technology (No. 2018KJXX-083), Natural Science Basic Research Plan of Shaanxi Province of China (Nos. 2018JM5161, 2018JQ5183, 2019JM-074), Scientific Research Program funded by Shaanxi Provincial Education Department (No. 19JK0543), and Outstanding Youth Science Fund of Xi'an University of Science and Technology (No. 2018YQ201).

Conflicts of Interest: The authors declare no conflict of interest.

\section{References}

1. Ranjith, P.; Zhao, J.; Ju, M.; De Silva, R.V.; Rathnaweera, T.; Bandara, A.K. Opportunities and challenges in deep mining: A brief review. Engineering 2017, 3, 546-551. [CrossRef]

2. Cai, M.; Brown, E.T. Challenges in the mining and utilization of deep mineral resources. Engineering 2017, 3, 432-433. [CrossRef] 
3. Dong, L.; Tong, X.; Li, X.; Zhou, J.; Wang, S.; Liu, B. Some developments and new insights of environmental problems and deep mining strategy for cleaner production in the mines. J. Clean. Prod. 2019, 210, 1562-1578. [CrossRef]

4. Khaldoun, A.; Ouadif, L.; Baba, K.; Bahi, L. Valorization of mining waste and tailings through paste backfilling solution, Imiter operation, Morocco. Int. J. Min. Sci. Technol. 2016, 26, 511-516. [CrossRef]

5. Zhai, X.; Xu, Y.; Yu, Z. Design and Performance Simulation of a Novel Liquid CO2 Cycle Refrigeration System for Heat Hazard Control in Coal Mines. J. Therm. Sci. 2019, 28, 585-595. [CrossRef]

6. Wang, M.; Liu, L.; Chen, L.; Zhang, X.; Zhang, B.; Ji, C. Cold load and storage functional backfill for cooling deep mine. Adv. Civ. Eng. 2018, 2018, 1-8. [CrossRef]

7. Zhang, X.; Jia, Y.; Wang, M.; Liu, L. Experimental research on heat transfer and strength analysis of backfill with ice grains in deep mines. Sustainability 2019, 11, 2486. [CrossRef]

8. Belle, B.; Biffi, M. Cooling pathways for deep Australian longwall coal mines of the future. Int. J. Min. Sci. Technol. 2018, 28, 865-875. [CrossRef]

9. Wang, C.; Huang, Z.; Lu, Y.; Tang, G.; Li, H. Influences of Reservoir Heterogeneity and Anisotropy on CO2 Sequestration and Heat Extraction for CO2-Based Enhanced Geothermal System. J. Therm. Sci. 2019, 28, 319-325. [CrossRef]

10. Benim, A.C.; Cicek, A.; Eker, A.M. A Computational Investigation of the Thermohydraulics of an EGS Project. J. Therm. Sci. 2018, 27, 405-412. [CrossRef]

11. Zhang, X.-Y.; Liu, L.; Liu, L.; Liu, L.; Jia, Y.-H. Numerical simulation of heat release performance of filling body under condition of heat extracted by fluid flowing in buried tube. J. Cent. South Univ. 2019, 26, 2160-2174. [CrossRef]

12. Liu, L.; Xin, J.; Zhang, B.; Zhang, X.Y.; Wang, M.; Qiu, H.F.; Chen, L. Basic theories and applied exploration of functional backfill in the mines. J. China Coal Soc. 2018, 43, 1811-1820.

13. Wang, M.; Liu, L.; Zhang, X.-Y.; Chen, L.; Wang, S.-Q.; Jia, Y.-H. Experimental and numerical investigations of the heat transfer and phase-change characteristics of cemented paste backfill with PCM. Appl. Therm. Eng. 2019, 150, 121-131. [CrossRef]

14. Pretorius, J.G.; Mathews, M.J.; Maré, P.; Kleingeld, M.; Van Rensburg, J. Implementing a DIKW model on a deep mine cooling system. Int. J. Min. Sci. Technol. 2019, 29, 319-326. [CrossRef]

15. Guo, P.; He, M.; Zheng, L.; Zhang, N. A geothermal recycling system for cooling and heating in deep mines. Appl. Therm. Eng. 2017, 116, 833-839. [CrossRef]

16. Du Plessis, G.E.; Arndt, D.C.; Mathews, E.H. The development and integrated simulation of a variable water flow energy saving strategy for deep-mine cooling systems. Sustain. Energy Technol. Assess. 2015, 10, 71-78. [CrossRef]

17. Lyu, W.; Li, X.; Yan, S.; Jiang, S. Utilizing shallow geothermal energy to develop an energy efficient HVAC system. Renew. Energy 2020, 147, 672-682. [CrossRef]

18. Falcone, G.; Liu, X.; Okech, R.R.; Seyidov, F.; Teodoriu, C. Assessment of deep geothermal energy exploitation methods: The need for novel single-well solutions. Energy 2018, 160, 54-63. [CrossRef]

19. Lei, Z.; Zhang, Y.; Zhang, S.; Fu, L.; Hu, Z.; Yu, Z.; Li, L.; Zhou, J. Electricity generation from a three-horizontal-well enhanced geothermal system in the Qiabuqia geothermal field, China: Slickwater fracturing treatments for different reservoir scenarios. Renew. Energy 2020, 145, 65-83. [CrossRef]

20. Olabi, A.G.; Mahmoud, M.; Soudan, B.; Wilberforce, T.; Ramadan, M. Geothermal based hybrid energy systems, toward eco-friendly energy approaches. Renew. Energy 2020, 147, 2003-2012. [CrossRef]

21. Wang, Y.; Liu, Y.; Dou, J.; Li, M.; Zeng, M. Geothermal energy in China: Status, challenges, and policy recommendations. Util. Policy 2020, 64, 101020. [CrossRef]

22. Mohamad, K.; Mohammed, A.K.; Ferri, H. Optimal utilization of geothermal heat from abandoned oil wells for power generation. Appl. Therm. Eng. 2019, 153, 536-542. [CrossRef]

23. Hu, X.; Banks, J.; Wu, L.; Liu, W.V. Numerical modeling of a coaxial borehole heat exchanger to exploit geothermal energy from abandoned petroleum wells in Hinton, Alberta. Renew. Energy 2020, 148, 1110-1123. [CrossRef]

24. Cheng, S.W.; Kurnia, J.C.; Ghoreishi-Madiseh, S.A.; Sasmito, A.P. Optimization of geothermal energy extraction from abandoned oil well with a novel well bottom curvature design utilizing Taguchi method. Energy 2019, 188, 116098. [CrossRef] 
25. Wang, Z.; Li, R.; Hu, J.; Hu, X.; Gu, Z. Experimental Study on Hybrid Organic Phase-change Materials Used for Solar Energy Storage. J. Therm. Sci. 2020. [CrossRef]

26. Mahdi, J.; Lohrasbi, S.; Ganji, D.D.; Nsofor, E.C. Simultaneous energy storage and recovery in the triplex-tube heat exchanger with PCM, copper fins and Al2O3 nanoparticles. Energy Convers. Manag. 2019, 180, 949-961. [CrossRef]

27. Pooria, P.; Siamak, H. Numerical study of a Phase-change Material (PCM) embedded solar thermal energy operated cool store: A feasibility study. Int. J. Refrig. 2020, 117, 114-123. [CrossRef]

28. Singh, R.P.; Kaushik, S.C.; Rakshit, D. Performance evaluation of charging process in a cascade latent heat storage system (C-LHSS) based on heat flux DSC results. Int. J. Therm. Sci. 2020, 151, 106274. [CrossRef]

29. Zayed, M.E.; Zhao, J.; Li, W.; Elsheikh, A.H.; Elbanna, A.M.; Jing, L.; Geweda, A. Recent progress in phase-change materials storage containers: Geometries, design considerations and heat transfer improvement methods. J. Energy Storage 2020, 30, 101341. [CrossRef]

30. Xu, Q.; Akkurt, N.; Zou, Z.; Liu, Y.; Feng, J.; Yu, C.; Ding, C.; Xiong, Y.; Zhou, J.; Zang, Y.; et al. Synthesis and Characterization of Disodium Hydrogen Phosphate Dodecahydrate-Lauric-Palmitic Acid Used for Indoor Energy Storage Floor Units. J. Therm. Sci. 2020. [CrossRef]

31. Xu, H.; Magro, F.D.; Sadiki, N.; Mancaux, J.-M.; Py, X.; Romagnoli, A. Compatibility study between aluminium alloys and alternative recycled ceramics for thermal energy storage applications. Appl. Energy 2018, 220, 94-105. [CrossRef]

32. Michał, R.; Ewa, K.R. Possibilities and benefits of a new method of modifying conventional building materials with phase-change materials (PCMs). Constr. Build. Mater. 2019, 211, 1013-1024. [CrossRef]

33. Qi, C.C.; Fourie, A. Cemented paste backfill for mineral tailings management: Review and future perspectives. Miner. Eng. 2019, 144, 106025. [CrossRef]

34. Sun, Q.; Tian, S.; Sun, Q.; Li, B.; Cai, C.; Xia, Y.; Wei, X.; Mu, Q. Preparation and microstructure of fly ash geopolymer paste backfill material. J. Clean. Prod. 2019, 225, 376-390. [CrossRef]

35. Sarı, A.; Bicer, A.; Al-Sulaiman, F.; Karaipekli, A.; Tyagi, V. Diatomite/CNTs/PEG composite PCMs with shape-stabilized and improved thermal conductivity: Preparation and thermal energy storage properties. Energy Build. 2018, 164, 166-175. [CrossRef]

36. Diani, A.; Campanale, M. Transient melting of paraffin waxes embedded in aluminum foams: Experimental results and modeling. Int. J. Therm. Sci. 2019, 144, 119-128. [CrossRef]

37. Zhang, S.; Feng, D.; Shi, L.; Wang, L.; Jin, Y.; Tian, L.; Li, Z.; Wang, G.; Zhao, L.; Yan, Y. A review of phase-change heat transfer in shape-stabilized phase-change materials (ss-PCMs) based on porous supports for thermal energy storage. Renew. Sustain. Energy Rev. 2021, 135, 110127. [CrossRef]

38. Qu, Y.; Wang, S.; Tian, Y.; Zhou, D. Comprehensive evaluation of Paraffin-HDPE shape stabilized PCM with hybrid carbon nano-additives. Appl. Therm. Eng. 2019, 163, 114404. [CrossRef]

39. Praveen, B.; Suresh, S.; Pethurajan, V. Heat transfer performance of graphene nano-platelets laden micro-encapsulated PCM with polymer shell for thermal energy storage based heat sink. Appl. Therm. Eng. 2019, 156, 237-249. [CrossRef]

40. Mankel, C.; Caggiano, A.; Koenders, E. Thermal energy storage characterization of cementitious composites made with recycled brick aggregates containing PCM. Energy Build. 2019, 202, 109395. [CrossRef]

41. Li, C.; Guan, Y.; Jiang, C.; Deng, S.; Lu, Z. Numerical study on the heat transfer, extraction, and storage in a deep-buried pipe. Renew. Energy 2020, 152, 1055-1066. [CrossRef]

42. El Ouali, A.; El Rhafiki, T.; Kousksou, T.; Allouhi, A.; Mahdaoui, M.; Jamil, A.; Zeraouli, Y. Heat transfer within mortar containing micro-encapsulated PCM: Numerical approach. Constr. Build. Mater. 2019, 210, 422-433. [CrossRef]

43. Buonomo, B.; Celik, H.; Ercole, D.; Manca, O.; Mobedi, M. Numerical study on latent thermal energy storage systems with aluminum foam in local thermal equilibrium. Appl. Therm. Eng. 2019, 159, 113980. [CrossRef]

44. Li, X.; Tong, C.; Duanmu, L.; Liu, L. Research on U-tube Heat Exchanger with Shape-stabilized Phase-change Backfill Material. Procedia Eng. 2016, 146, 640-647. [CrossRef]

(C) 2020 by the authors. Licensee MDPI, Basel, Switzerland. This article is an open access article distributed under the terms and conditions of the Creative Commons Attribution (CC BY) license (http://creativecommons.org/licenses/by/4.0/). 